\title{
Stalled at the Intersection: Insurance Status and Disparities in Post Mastectomy Breast Reconstruction
}

Orli Friedman-Eldar ( $\square$ eldaror@gmail.com ) Jackson Memorial Hospital https://orcid.org/0000-0003-4390-6139 Jonathan Burke

University of Miami Miller School of Medicine: University of Miami School of Medicine lago de Castro Silva

University of Miami Miller School of Medicine: University of Miami School of Medicine Camille C Baumrucker

University of Miami Miller School of Medicine: University of Miami School of Medicine

\section{Fernando Valle}

University of El Salvador: Universidad de El Salvador

\section{Anne-Sophie Lessard}

University of Miami Miller School of Medicine: University of Miami School of Medicine

Wrood Kassira

University of Miami Miller School of Medicine: University of Miami School of Medicine

\section{Dido Franceschi}

University of Miami Miller School of Medicine: University of Miami School of Medicine

\section{Susan B Kesmodel}

University of Miami Miller School of Medicine: University of Miami School of Medicine Eli Avisar

University of Miami Miller School of Medicine: University of Miami School of Medicine Neha Goel

University of Miami Miller School of Medicine: University of Miami School of Medicine Mecker G Möller

University of Miami Miller School of Medicine: University of Miami School of Medicine

\section{Research Article}

Keywords: Breast cancer, mastectomy, reconstruction, insurance, disparities

Posted Date: August 26th, 2021

DOI: https://doi.org/10.21203/rs.3.rs-813168/v1 
License: (c) (1) This work is licensed under a Creative Commons Attribution 4.0 International License. Read Full License

Version of Record: A version of this preprint was published at Journal of the American College of Surgeons on October 1st, 2020. See the published version at https://doi.org/10.1016/j.jamcollsurg.2020.07.025. 


\section{Abstract}

\section{Purpose}

Post-mastectomy breast reconstruction (PMBR) is an important component of breast cancer treatment, but disparities relative to insurance status persist despite legislation targeting the issue. We aimed to study this relationship in a large health system combining a safety net hospital and a private academic center.

Methods

Data were collected on all patients who underwent mastectomy for breast cancer from 2011-2019 in a private academic center and an adjacent public safety-net hospital served by same surgical teams. Multivariable logistic regression was used to assess the effect of insurance status on PMBR, controlling for covariates that included socioeconomic, demographic, and clinical factors.

Results

Of 1,554 patients undergoing mastectomy for breast cancer, 753 (48.5\%) underwent PMBR. Out of them, 741 had insurance type recorded, with 592 (79.9\%) privately insured patients, 50 (6.7\%) Medicare, 68 (9.2\%) Medicaid, and 31 (4.2\%) uninsured patients. Multivariable logistic regression showed a significantly lower likelihood of undergoing PMBR for uninsured (OR 6.9, 95\% Cl: 4.1-11.7; $p<0.0001$ ), Medicare (OR 2.0, (5\% Cl: 1.2-3.3; $\mathrm{p}=0.004)$, and Medicaid (OR 1.7, 95\% Cl:1.1-2.7; $\mathrm{p}=0.02$ ) patients, compared with privately insured patients. Age, stage, race, and hospital type confounded this relationship.

Conclusion

Patients without health insurance have dramatically reduced access to PMBR compared to those with private insurance. Expanding access to this important procedure is essential to achieve greater health equity for breast cancer patients.

\section{Introduction}

It is estimated that over 275,000 new cases of breast cancer will be diagnosed in 2020 in the United States [1]. Of these, around one third will undergo mastectomy [2, 3]. Post-mastectomy breast reconstruction (PMBR) is an essential aspect of care for breast cancer, conferring a variety of benefits for patients. These include the restoration of breast appearance [4], alleviation of psychological distress [4, 5], improvement of self-esteem [6], and enhancement of quality of life [4, 7]. While around half or more of women undergoing mastectomy may prefer PMBR [8], in the United States actual rates have historically been considerably lower, ranging from around $10-15 \%$ in the late 1990 's to early 2000 's $[2,9]$. 
In 1997, Medicare began to cover PMBR for breast cancer, and the Women's Health and Cancer Rights Act (WHCRA) of 1998 mandated coverage of PMBR by private insurers. Many states, including Florida, later mandated Medicaid coverage of PMBR as well [10-12]. While the WHCRA helped increased PMBR rates, albeit mostly in states without prior legislation requiring coverage for the procedure [13], many patients are still unable to access PMBR. The most recent rates are estimated to be around $35-40 \%[2,3]$, but stark disparities in PMBR exist, particularly surrounding socioeconomic factors such as race $[14,15]$, educational level [16], and insurance status [14, 17]. In fact, these disparities have persisted or even increased following the implementation of the WHCRA [18], leaving many patients without the option to undergo this important procedure.

Previous research examining the effect of insurance status on PMBR rates has utilized state and national databases. While these other investigations give a more global view, a real-world perspective of how insurance status affects access to care in a local population is lacking. This study aims to fill this gap in the literature by examining the local effect of insurance status on PMBR rates in a public, safety-net hospital and an adjacent private academic center.

\section{Methods}

\section{Study Design}

This is an observational cohort study of patients undergoing mastectomy using a multi-hospital institutional database. The study was approved by the institutional review board. We retrospectively collected data from the charts of all patients undergoing mastectomy at the local public safety-net hospital and private university hospital between 2011-2019. The same multidisciplinary team composed of surgical oncologists, plastic surgeons, medical oncologist, radiation oncologist cover and evaluate the patients at both institutions. The same team of surgical oncologist and plastic surgeons operate at both hospitals and do not have a greater incentive at either hospital to arrange for and/or perform PMBR. This article adheres to the Strengthening the Reporting of Observational Studies in Epidemiology (STROBE) checklist for cohort studies [19].

\section{Patient Selection}

All patients undergoing mastectomy from 2011 to 2019 were identified in the institutional medical records using the primary Current Procedural Terminology (CPT) codes for simple mastectomy (19303), subcutaneous mastectomy (19304), radical mastectomy (19305-19306), and modified radical mastectomy (19307). Male patients and patients undergoing mastectomy for indications unrelated to cancer, such as gynecomastia or gender-affirming surgery, were excluded.

\section{Exposure and Potential Confounding Variables}

Inclusion criterion for all variables was the presence of $80 \%$ or more data for all records in the patient sample to prevent the need for extensive imputation. We categorized the primary exposure variable, insurance status, as uninsured/self-pay, Medicare, Medicaid, and privately insured. We identified potential 
confounding variables based on demonstrated relationships with PMBR rates in the literature and our institution's clinical experience. We then developed a Directed Acyclic Graph (DAG) to determine which variables should be assessed as potential confounding variables in the multivariable model. These included demographic variables (age, race/ethnicity, income) [14, 18], comorbidities (Body Mass Index [BMI], Diabetes) [20, 21], perioperative factors (stage, functional status, neoadjuvant chemotherapy) [22], hospital type, and behavioral risk factors (smoking) for breast implant complications and failure [23].

We categorized race/ethnicity as non-Hispanic Black, non-Hispanic White, Hispanic, and Other, according to self-identified race in the medical record. As done in previous studies [18], income was inferred from the patients' self-listed zip code associated with their address based on the median income for each zip code as recorded in the publicly accessible 2017 Florida Census [24]. Functional status was assessed using the recorded American Society of Anesthesiologists (ASA) physical status classification system [25]. We determined stage using the American Joint Committee on Cancer (AJCC) 8th Edition criteria [26] and limited categorizations to the five numbered stages along with prophylactic and other (for cancer types other than adenocarcinoma such as Phyllodes tumors where the staging does not apply). We likewise determined nodal status and utilized N0, N1 (including microscopic N1), and N2-3, as has been done in previous studies assessing the effect of nodal status on radiation therapy [27], which also influences decision making with PMBR [28]. We categorized smoking status as current, former, and never. Continuous variables, including age, income, and BMI were grouped into deciles and plotted against the log odds for PMBR to assess for linearity. Income was retained as continuous variables while BMI was subsequently categorized according to standard measures [29] and age categorized empirically into < 50 , $50-70$, and $\geq 70$ years-old. All flap reconstructions were done physically at the public hospital, however, for the purpose of this study, a patient that was seen in the private hospital and underwent a flap reconstruction was still considered as a private facility patient.

\section{Clinical End Point}

The primary outcome was the occurrence of PMBR, utilizing immediate or delayed reconstruction with either tissue expanders, implants, or flaps.

\section{Addressing Potential Sources of Bias}

In order to reduce selection bias, we included data from two hospitals with the same surgeons, minimizing practice variations. We also included only female patients undergoing mastectomy for an indication related to breast cancer. We utilized objective insurance data from the charts and a careful review of post-mastectomy care for patients not undergoing PMBR to identify delayed reconstruction and prevent misclassification bias.

\section{Statistical Analysis}

Exposure variables were characterized using frequency and percentage of categorical variables and mean and standard deviation for continuous variables. Associations with the main outcome were determined in univariable analyses using the chi-squared test or Student's $t$ test as appropriate. Potential 
confounding variables with $p<0.10$ were included in multivariable logistic regression, and those variables that did not meet that criteria but were determined to have sufficient potential for confounding based on past literature and/or clinical expertise were also included.

A multivariable logistic regression model accounting for covariates was used to assess the effect of insurance status on PMBR rates, and the effect was considered statistically significant if $p<0.05$.

Confounding was assessed by removing a potential confounding variable from the model and examining any change in effect size of the primary exposure variable, with a $10 \%$ difference considered to be significant. Sensitivity analyses were performed to see the effect of excluding the potential confounding variables with the most missing data (i.e., ASA status and income). Post-hoc secondary analysis was done to assess for interaction by race. Data were analyzed using SAS 9.4 (SAS institute, Cary, NC).

\section{Results}

Of 1,802 total patients undergoing mastectomy, 1,554 met inclusion criteria for analysis as specified above (Fig. 1). The overall patient population had a mean age of 53.9 years, and the majority were Hispanic (59.5\%) with substantial proportions of non-Hispanic Black (17.9\%) and non-Hispanic White (20.9\%) patients. The majority of patients, $68.3 \%(n=1,061)$, had early-stage disease (Stage 0 -II), while $22.5 \%(n=350)$ had Stage III, and 4.3\% $(n=67)$ had stage IV disease. Patients without insurance were more likely to be Hispanic and have a lower income (Table 1). 
TABLE 1 Demographic and baseline characteristics of patients undergoing mastectomy by insurance status $(\mathrm{N}=1530)$

\begin{tabular}{|c|c|c|c|c|c|}
\hline & $\begin{array}{l}\text { Private } \\
\text { Insurance } \\
\mathrm{N}=932(60.9 \%)\end{array}$ & $\begin{array}{l}\text { Medicare } \\
\mathrm{N}=170(11.1 \%)\end{array}$ & $\begin{array}{l}\text { Medicaid } \\
\mathrm{N}=195(12.8 \%)\end{array}$ & $\begin{array}{l}\text { Uninsured } \\
\mathrm{N}=233(15.2 \%)\end{array}$ & $p$ value \\
\hline Age (years) & & & & & $<0.0001$ \\
\hline$<50$ & 392 (42.1) & $8(4.7)$ & $81(41.5)$ & 87 (37.3) & \\
\hline $50-70$ & $488(52.4)$ & $76(44.7)$ & $110(56.4)$ & $128(54.9)$ & \\
\hline$>70$ & $52(5.6)$ & $86(50.6)$ & $4(2.1)$ & $18(7.7)$ & \\
\hline Race & & & & & $<0.0001$ \\
\hline Hispanic & $512(56.0)$ & $90(53.6)$ & $121(62.7)$ & $173(74.9)$ & \\
\hline $\begin{array}{l}\text { Non- } \\
\text { Hispanic Black }\end{array}$ & 165 (18.1) & 20 (11.9) & $52(27.0)$ & 33 (14.3) & \\
\hline $\begin{array}{l}\text { Non- } \\
\text { Hispanic White }\end{array}$ & 219 (24.0) & 57 (33.9) & $18(9.3)$ & $20(8.7)$ & \\
\hline Other & $18(2.0)$ & $1(0.6)$ & $2(1.0)$ & $5(2.2)$ & \\
\hline $\begin{array}{l}\text { Income } \\
\text { (Dollars) }\end{array}$ & $\begin{array}{l}50,603 \\
(42,306- \\
65,041)\end{array}$ & $\begin{array}{l}48,420 \\
(35,131- \\
65,581)\end{array}$ & $\begin{array}{l}43,369 \\
(34,088- \\
53,546)\end{array}$ & $\begin{array}{l}43,439 \\
(31,010- \\
51,738)\end{array}$ & $<0.0001$ \\
\hline Public Hospital & $246(26.4)$ & $42(24.7)$ & $154(79.0)$ & $220(94.4)$ & $<0.0001$ \\
\hline Stage & & & & & $<0.0001$ \\
\hline 0 & 153 (16.4) & $28(16.5)$ & $17(8.7)$ & $28(12.0)$ & \\
\hline I & $230(24.7)$ & $39(22.9)$ & 33 (16.9) & $41(17.6)$ & \\
\hline II & $286(30.7)$ & $53(31.2)$ & 66 (33.9) & $76(32.6)$ & \\
\hline III & $171(18.3)$ & $32(18.8)$ & $64(32.8)$ & 73 (31.3) & \\
\hline IV & $35(3.8)$ & $11(6.5)$ & $11(5.7)$ & $10(4.3)$ & \\
\hline Prophylactic & $42(4.5)$ & $6(3.5)$ & $1(0.5)$ & $2(0.9)$ & \\
\hline $\begin{array}{c}\text { Not } \\
\text { Applicable }\end{array}$ & $15(1.6)$ & $1(0.6)$ & $3(1.5)$ & $3(1.3)$ & \\
\hline Nodal Status & & & & & $<0.0001$ \\
\hline NO & $554(60.0)$ & $108(65.5)$ & $100(53.5)$ & $122(53.0)$ & \\
\hline $\mathrm{N} 1$ & 197 (21.3) & 32 (19.4) & $38(20.3)$ & $70(30.4)$ & \\
\hline
\end{tabular}




\begin{tabular}{|c|c|c|c|c|c|}
\hline N2-N3 & $115(12.5)$ & $18(10.9)$ & 45 (24.1) & $33(14.4)$ & \\
\hline $\begin{array}{c}\text { Not } \\
\text { Applicable }\end{array}$ & $57(6.2)$ & $7(4.2)$ & $4(2.1)$ & $5(2.2)$ & \\
\hline NACT & $291(31.2)$ & $43(25.3)$ & $93(47.7)$ & $88(37.8)$ & $<0.0001$ \\
\hline Diabetes & $96(10.3)$ & $50(29.4)$ & $26(13.3)$ & $30(12.9)$ & $<0.0001$ \\
\hline Smoking & & & & & $<0.0001^{`}$ \\
\hline $\begin{array}{l}\text { Current } \\
\text { Smoker }\end{array}$ & $64(6.9)$ & $11(6.5)$ & $17(8.7)$ & $22(9.4)$ & \\
\hline $\begin{array}{l}\text { Former } \\
\text { Smoker }\end{array}$ & $131(14.1)$ & $42(24.7)$ & $19(9.8)$ & $16(6.9)$ & \\
\hline $\begin{array}{l}\text { Never } \\
\text { Smoker }\end{array}$ & 735 (79.0) & $117(68.8)$ & $159(81.5)$ & 195 (83.7) & \\
\hline BMI & & & & & 0.0025 \\
\hline$<25$ & $343(36.8)$ & $49(28.8)$ & $44(22.6)$ & $70(30.0)$ & \\
\hline $30 \geq 25$ and $<$ & $302(32.4)$ & 53 (31.2) & 79 (40.5) & $83(35.6)$ & \\
\hline$<35 \geq 30$ and & $186(20.0)$ & $51(30.0)$ & $44(22.6)$ & $54(23.2)$ & \\
\hline$<40 \geq 35$ and & $71(7.6)$ & $10(5.9)$ & $15(7.6)$ & $13(5.6)$ & \\
\hline$\geq 40$ & $30(3.2)$ & $7(4.1)$ & $13(6.7)$ & $13(5.6)$ & \\
\hline ASA Score & & & & & $<0.0001$ \\
\hline ASA 1 & $23(2.8)$ & $1(0.6)$ & $1(0.5)$ & $4(1.7)$ & \\
\hline ASA 2 & $559(68.3)$ & $88(52.1)$ & $124(69.7)$ & 165 (72.1) & \\
\hline ASA 3 & 231 (28.3) & $76(45.0)$ & $51(28.7)$ & $60(26.2)$ & \\
\hline ASA 4 & $5(0.6)$ & $4(2.4)$ & $2(1.1)$ & $0(0.0)$ & \\
\hline
\end{tabular}

The percentages in each category are calculated after mapping out the missing data for each variable. Age expressed as mean (SD), income expressed as median (IQR). Categorical variables expressed as frequency (\%), ASA American Society of Anesthesiologists, BMIBody Mass Index, NACT neoadjuvant chemotherapy.

Overall, 48.5\% ( $n=753$ ) of patients underwent PMBR, 741 of them had insurance type recorded, with 79.9\% $(n=592)$ privately insured, 6.7\% $(n=50)$ Medicare, 9.2\% $(n=68)$ Medicaid, and 4.2\% $(n=31)$ uninsured patients. Type of reconstruction was known for 737 patients in the PMBR group, 664 (90\%) of 
them underwent immediate reconstruction (446 received tissue expanders, 178 direct implants, and 40 free flaps) and $73(10 \%)$ underwent delayed reconstruction. Patients that underwent PMBR were more likely to be of non-Hispanic White race/ethnicity, to have earlier stage disease, and to have fewer comorbidities than those that did not. Univariable analyses demonstrated statistically significant associations between insurance status and PMBR $(p<0.0001)$, as well as for all co-variates except for smoking $(p=0.32)$ (Table 2). 
Table 2

Univariable analyses of relationship between insurance status and potential confounders with PMBR

PMBR

$N=753(48.5)$

Age (years)

$<50$

$50-70$

$>70$

Insurance

Private Insurance

Medicare

Medicaid

Uninsured

Race

Non-Hispanic Black

Hispanic

Non-Hispanic White

Other

Income (Dollars)

Public Hospital

Stage

0

I

II

III

IV

Prophylactic

Not Applicable

The percentages in each category are calculated after excluding the missing data for each variable. ASA American Society of Anesthesiologists, BMI Body Mass Index, NACT neoadjuvant chemotherapy, PMBR Post-mastectomy breast reconstruction.
No PMBR

$p$ value

$N=801(51.5 \%)$

$<0.0001$

$205(25.6)$

$469(58.6)$

$127(15.9)$

$<0.0001$

$340(43.1)$

$120(15.2)$

127 (16.1)

$202(25.6)$

$<0.0001$

$182(23.3)$

$469(60.1)$

$114(14.6)$

$15(1.9)$

$44,241(35,760-55,444) \quad<0.0001$

$493(61.6)$

$<0.0001$

$<0.0001$

$81(10.1)$

$128(16.0)$

254 (31.7)

$258(32.2)$

$57(7.1)$

$13(1.6)$

$10(1.3)$
$12(1.6)$ 


\begin{tabular}{|c|c|c|c|}
\hline & $\begin{array}{l}\text { PMBR } \\
\mathrm{N}=753 \text { (48.5) }\end{array}$ & $\begin{array}{l}\text { No PMBR } \\
\mathrm{N}=801(51.5 \%)\end{array}$ & $p$ value \\
\hline Nodal Status & & & $<0.0001$ \\
\hline NO & 506 (67.8) & $386(49.3)$ & \\
\hline N1 & 135 (18.1) & 209 (26.7) & \\
\hline N2-N3 & $52(7.0)$ & 165 (21.1) & \\
\hline Not Applicable & $53(7.1)$ & $23(2.9)$ & \\
\hline NACT & $182(24.2)$ & 339 (42.3) & $<0.0001$ \\
\hline Diabetes & $57(7.6)$ & 148 (18.5) & $<0.0001$ \\
\hline Smoking & & & 0.32 \\
\hline Current Smoker & $51(6.8)$ & $66(8.3)$ & \\
\hline Former Smoker & $113(15.0)$ & $104(13.0)$ & \\
\hline Never Smoker & 588 (78.2) & $630(78.8)$ & \\
\hline BMI & & & $<0.0001$ \\
\hline$<25$ & 299 (39.7) & $216(27.0)$ & \\
\hline$\geq 25$ and $<30$ & 254 (33.7) & $272(34.0)$ & \\
\hline$\geq 30$ and $<35$ & 133 (17.7) & 205 (25.6) & \\
\hline$\geq 35$ and $<40$ & $49(6.5)$ & $60(7.5)$ & \\
\hline$\geq 40$ & $18(2.4)$ & $48(6.0)$ & \\
\hline ASA Score & & & $<0.0001$ \\
\hline ASA 1 & $20(3.1)$ & $9(1.2)$ & \\
\hline ASA 2 & 466 (72.7) & 479 (61.9) & \\
\hline ASA 3 & $155(24.2)$ & $275(35.5)$ & \\
\hline ASA 4 & $0(0.0)$ & $11(1.4)$ & \\
\hline $\begin{array}{l}\text { The percentages } \\
\text { ASA American S } \\
\text { PMBR Post-mas }\end{array}$ & $\begin{array}{l}\text { ategory are cal } \\
\text { anesthesiologis } \\
\text { reast reconstru }\end{array}$ & $\begin{array}{l}\text { uding the missing } \\
\text { ss Index, NACT ne }\end{array}$ & $\begin{array}{l}\text { variable. } \\
\text { motherapy, }\end{array}$ \\
\hline
\end{tabular}

Multivariable logistic regression controlling for age, race, income, comorbidities, functional status, stage, nodal status, and neoadjuvant chemotherapy demonstrated a persistent effect of insurance status on PMBR, with privately insured patients having 6.9 times the odds (95\% Confidence Interval [Cl]: 4.1-11.7, 
$p<0.0001$ ) of undergoing PMBR as uninsured patients (Table 3 ). There were smaller, yet still statistically significant greater odds of undergoing PMBR for privately insured patients compared to both Medicare (Odds Ratio [OR] 2.0, 95\% Cl: 1.2-3.3; $p=0.004$ ) and Medicaid (OR 1.7, 95\% Cl: 1.1-2.7; $p=0.02$ ). Age, stage, race, and hospital type confounded the relationship, while diabetes, BMI, ASA status, smoking, income, and nodal status did not. Sensitivity analysis revealed little effect $(<10 \%)$ on the primary effect measure after exclusion of the two variables with the greatest number of missing data (income and ASA status). After excluding both these variables, there were only $4.9 \%(n=76)$ of records with missing data. Post-hoc analysis showed that neither race $(p=0.89)$ nor nodal status $(p=0.30)$ modified the relationship between insurance status and PMBR. 
Table 3

Multivariable logistic model for not undergoing PMBR.

\begin{tabular}{|c|c|c|}
\hline Variable & OR $(95 \% \mathrm{Cl})$ & $p$ value \\
\hline Insurance & & $<0.0001$ \\
\hline Uninsured & $6.9(4.1-11.7)$ & \\
\hline Medicaid & $1.7(1.1-2.7)$ & \\
\hline Medicare & $2.0(1.2-3.3)$ & \\
\hline Private (Ref) & 1. 0 & \\
\hline Age (years) & & $<0.0001$ \\
\hline$>70$ & $14.8(8.0-27.5)$ & \\
\hline $50-70$ & $3.4(2.4-4.8)$ & \\
\hline$<50$ (Ref) & 1.0 & \\
\hline Race/Ethnicity & & 0.0002 \\
\hline Non-Hispanic Black & $2.9(1.7-4.9)$ & \\
\hline Hispanic & $1.4(1.0-2.1)$ & \\
\hline Other & $3.0(0.9-9.7)$ & \\
\hline Non-Hispanic White (Ref) & 1. 0 & \\
\hline Income ( $\$ 10,000$ increase) & $1.0(0.9-1.0)$ & 0.303 \\
\hline Public Hospital & $3.5(2.5-4.9)$ & $<0.0001$ \\
\hline Stage & & $<0.0001$ \\
\hline 0 & $0.8(0.5-1.2)$ & \\
\hline I (Ref) & 1. 0 & \\
\hline II & $1.8(1.2-2.9)$ & \\
\hline III & $4.8(2.3-10.0)$ & \\
\hline IV & $9.8(3.5-27.9)$ & \\
\hline Prophylactic & $0.9(0.3-2.4)$ & \\
\hline Not Applicable & $1.9(0.6-5.6)$ & \\
\hline Diabetes & $1.4(0.9-2.1)$ & 0.174 \\
\hline
\end{tabular}

ASA American Society of Anesthesiologists, BMIBody Mass Index, C/Confidence Interval, NACT neoadjuvant chemotherapy, OR Odds Ratio, PMBR Post-mastectomy breast reconstruction. 


\begin{tabular}{|c|c|c|}
\hline Variable & OR $(95 \% \mathrm{Cl})$ & $p$ value \\
\hline BMI & & 0.204 \\
\hline$<25$ (Ref) & 1. 0 & \\
\hline$\geq 25$ and $<30$ & $0.9(0.7-1.3)$ & \\
\hline$\geq 30$ and $<35$ & $1.0(0.7-1.6)$ & \\
\hline$\geq 35$ and $<40$ & $1.2(0.7-2.2)$ & \\
\hline$\geq 40$ & $2.4(1.1-5.3)$ & \\
\hline ASA Score & & 0.288 \\
\hline ASA 1 (Ref) & 1.0 & \\
\hline ASA 2 & $1.0(0.4-2.7)$ & \\
\hline ASA 3 & $1.3(0.5-3.8)$ & \\
\hline ASA 4 & $>999.99(<0.001->999.99)$ & \\
\hline Nodal Status & & 0.683 \\
\hline NO (Ref) & 1.0 & \\
\hline N1 & $1.1(0.7-1.8)$ & \\
\hline N2-N3 & $1.4(0.7-2.7)$ & \\
\hline NACT & $1.1(0.8-1.7)$ & 0.542 \\
\hline
\end{tabular}

\section{Discussion}

This study demonstrates the dramatic effects of insurance status on PMBR utilization. This affirms the global relationship demonstrated in previous studies $[14,18,30]$ in a local, real-world context in urban teaching hospitals, with lack of insurance resulting in far less access to PMBR. Based on prior literature showing the substantial effect of PMBR on various quality of life measures [4-7], it is reasonable to infer that this lack of access translates to significantly poorer health outcomes after mastectomy for uninsured patients.

While Medicare and Medicaid both cover the procedure in our state, patients with private insurance were significantly more likely to undergo PMBR compared to those with Medicare (OR 2.0, 95\% Cl: 1.2-3.3; $p=$ $0.004)$ and Medicaid (OR 1.7, 95\% Cl: $1.1-2.7 ; \mathrm{p}=0.02)$. The effect was much more dramatic for uninsured patients $(\mathrm{OR}=6.9,95 \% \mathrm{Cl}: 4.1-11.7 ; \mathrm{p}<0.0001)$. Like other health disparities that exist for uninsured patients, such as in cancer survival [31] and major complications after general surgery 
procedures [32], this may be partially attributed to lack of access to consistent, high-quality primary and preventive care leading to more advanced disease. In this study, the difference of effect for governmentinsured patients with inclusion of stage in the model supports this notion. Indeed, more advanced stage may be viewed as a mediator in the relationship between insurance status and PMBR, as lack of insurance can prevent access to screening mammography, leading to a later stage breast cancer at presentation that may be less eligible for reconstruction.

Medicare patients had significantly higher rates of comorbidities including diabetes and increased ASA score (Table 1) that often accompany advanced age, yet even after stratifying by age in the raw data, about half the proportion of patients $\geq 70$ years-old with Medicare underwent PMBR compared to those with private insurance (16.3\% vs $32.7 \%$ ). After controlling for age and the other confounders in multivariable analysis, these patients still had significantly lower odds of undergoing PMBR.

Age, race, and hospital type substantially confounded the relationship between insurance status and PMBR, demonstrating the important intersection between insurance status and these other factors. Specifically, Non-Hispanic Black patients were significantly less likely to undergo PMBR (Table 3), a fact that has impact on insurance status as part of the well-established association between Black race and lower socioeconomic status [33]. The large effect of age on PMBR (OR 14.9, 95\% Cl: 8.0-27.5 for age $\geq 70$ compared to $<50$ ) is reflected in its considerable confounding on the relationship between insurance and PMBR, particularly with Medicare patients ( $112 \%$ decrease in effect size when including age). Interestingly, income did not confound the effect of insurance on PMBR, likely because income and insurance status are often intertwined with socioeconomic status.

The distribution of uninsured and insured patients at each hospital highlights the differences in access to care. A private academic center, serving primarily privately insured patients, allows for PMBR to most patients who may desire it, while the need to provide a large proportion of care as charity care in a public, safety-net hospital strains financial resources $[34,35]$ and may restrict funding for the procedure. Indeed, the safety-net hospital in this study previously provided PMBR to all patients regardless of insurance status, but lack of adequate funding in recent years necessitated cutting services, including PMBR. Still, after inclusion of hospital type, there is a $110 \%$ decrease in effect size for Medicaid patients and $37 \%$ decrease for uninsured patients, indicating that the public hospital mitigates the disparities for both these groups.

This is the first study to our knowledge to demonstrate the disparity in undergoing PMBR for uninsured patients adjusting for a broad range of salient clinical and social factors in a local, real-world setting. Previous research utilizing statewide and national administrative and clinical databases $[14,18,30,36]$ lacked the perspective of showing the on-the-ground effects of insurance status in a particular community. Further, in this study the same surgeons work at both institutions without financial incentive based on volume, which minimizes provider dependent differences in practice that may exist in research utilizing state or national databases. Taken together with the research based on broader data, our data supports the persisting disparities in PMBR surrounding insurance status. Still, generalizability from this 
study may be limited for other localities given the impact of local policy, such as state or local funding for PMBR that may exist elsewhere.

While state and federal legislation over the past decades has significantly expanded access to PMBR through mandated coverage by private [11] and government insurance [10], past literature as well as this study show that considerable disparities persist $[14,18,37]$. Lack of health insurance in particular has repeatedly been shown to be a major contributing factor $[14,18,36]$. Coverage of the procedure increases access and leads to substantially higher PMBR rates. This can be seen following the aforementioned US legislation [13] and perhaps most clearly in countries with nationalized health insurance such as Korea, where there was a dramatic increase in PMBR rates (from 4-52\%) following the institutional coverage of the procedure [38].

Disparities in access to PMBR represent but one example of the compounded adverse health effects of lack of insurance in the US. These range from more frequent and more severe chronic medical conditions like hypertension to financial hardship including involuntary job loss to higher mortality from both acute injury and chronic disease $[39,40]$. As described above, one mechanism in which lack of insurance causes poor health outcomes is through inhibiting access to preventive care and treatment [41-43]. The morbidity and mortality burden disproportionately falls on historically disadvantaged communities, including Black and Hispanic [44], undocumented [45, 46], and/or Transgender [47] people. While incremental policy changes such as the WHCRA and the Affordable Care Act (ACA) have partially ameliorated the problem by mandating coverage of PMBR for those with insurance and reducing the number of uninsured [13], approximately 30 million people in the United States remain uninsured [48].

Our study has several limitations. First, there is a potential for bias with the missing data (Fig. 1), although the data for the primary exposure and outcome variables was nearly complete, and the other missing data for confounding variables likely was missing at random. Additionally, there was minimal impact of removing the two variables (ASA status and income) that made up the vast majority of the missing data on the primary effect size. Loss to follow up may have occurred if patients underwent reconstruction at an outside hospital, died before a planned reconstruction, or were scheduled for delayed reconstruction after the time of data collection, but based on review of the records is presumed to be minimal. The patient charts also did not consistently document patient preference, so it is difficult to determine whether some patients did not undergo PMBR because they did not want to rather than because they did not have access to it. Still, given historical PMBR rates and disparities as well as the drastically different rates between the insurance statuses, it is unlikely that this would significantly confound the analysis. Finally, the analysis lacks immigration status, which could be an important confounding variable but cannot be determined from the records.

Future directions should include state by state variations in PMBR rates to assess the effect of Medicaid expansion through the ACA. Additionally, data examining the disparities in PMBR faced by undocumented patients would be useful, particularly in the setting of local interventions to allow access to PMBR for this population. Finally, Community Based Participatory Research involving uninsured 
patients that lack access to PMBR would be helpful to assess their perception of the problem and what priorities they would like to see targeted through policy and/or interventions.

\section{Conclusions}

In a large public and private hospital system, served by the same surgeons, patients without health insurance have dramatically reduced access to PMBR compared to those with private insurance. Further expanding access to this important procedure is essential to achieve greater PMBR equity for breast cancer patients.

\section{Abbreviations}

PMBR, Post-mastectomy breast reconstruction

OR, Odds Ratio

$\mathrm{Cl}$, Confidence Interval

WHCRA, Women's Health and Cancer Rights Act

STROBE, Strengthening the Reporting of Observational Studies in Epidemiology

CPT, Current Procedural Terminology

DAG, Directed Acyclic Graph

BMI, Body Mass Index

ASA, American Society of Anesthesiologists

AJCC American Joint Committee on Cancer

ACA, Affordable Care Act

\section{Declarations}

\section{Ethics approval}

This study was performed in line with the principles of the Declaration of Helsinki. Approval was granted by the institutional Ethics Committee No. 20053311.

\section{Funding}

The authors received no financial support for the research, authorship, and/or publication of this article. 


\section{Conflicts of interest/Competing interests}

Authors declare that they have no conflict of interest.

\section{Consent to participate and consent for publication}

Not applicable

\section{Availability of data and material}

The datasets generated and analyzed during the current study are available from the corresponding author on reasonable request.

\section{Code availability}

Available from the corresponding author on reasonable request.

\section{Authors' contributions}

Study Conception and design: Orli Fredman-Eldar, Jonathan Burke and Mecker G Möller. Manuscript preparation, data collection and analysis: by Orli Friedman-Eldar, Jonathan Burke, lago de Castro Silva, Camille C Baumrucker, Fernando Valle Reyes and Mecker G Möller. All authors read, reviewed, and approved the final manuscript.

\section{References}

1. Surveillance, Epidemiology, and End Results Program. Cancer Stat Facts: Female Breast Cancer. National Cancer Institute. Updated 2020. Available at: https://seer.cancer.gov/statfacts/html/breast.html. Accessed November 17, 2020.

2. Kummerow KL, Du L, Penson DF et al (2015) Nationwide trends in mastectomy for early-stage breast cancer. JAMA Surg; 150: 9-16. doi:10.1001/jamasurg.2014.2895

3. Mahmood U, Hanlon AL, Koshy M et al (2013) Increasing national mastectomy rates for the treatment of early stage breast cancer. Ann Surg Oncol; 20: 1436-1443. doi: 10.1245/s10434-012-2732-5

4. Cagli B, Cogliandro A, Barone M, Persichetti P (2014) Quality-of-life outcomes between mastectomy alone and breast reconstruction: comparison of patient-reported BREAST-Q and other health-related quality-of-life measures. Plast Reconstr Surg. Apr;133(4):594e-5e. doi: 10.1097/PRS.0000000000000031

5. Fanakidou I, Zyga S, Alikari V et al (2018). Mental health, loneliness, and illness perception outcomes in quality of life among young breast cancer patients after mastectomy: the role of breast reconstruction. Qual Life Res; 27: 539-543. doi: 10.1007/s11136-017-1735-x 
6. Markopoulos C, Tsaroucha AK, Kouskos E et al (2009). Impact of breast cancer surgery on the selfesteem and sexual life of female patients. J Int Med Res; 37: 182-188. doi:

$10.1177 / 147323000903700122$

7. Dauplat J, Kwiatkowski F, Rouanet P et al (2017). Quality of life after mastectomy with or without immediate breast reconstruction. Br J Surg; 104: 1197-1206. doi: 10.1002/bjs.10537

8. Keith DJ, Walker MB, Walker LG et al (2003) Women who wish breast reconstruction: characteristics, fears, and hopes. Plast Reconstr Surg; 111: 1051-1056; discussion 1057-1059. doi:

10.1097/01.PRS.0000046247.56810.40

9. Alderman AK, McMahon L, Jr., Wilkins EG (2003). The national utilization of immediate and early delayed breast reconstruction and the effect of sociodemographic factors. Plast Reconstr Surg; 111: 695703; discussion 704-695. doi:10.1097/01.PRS.0000041438.50018.02

10. Centers for Medicare \& Medicaid Services: Breast Reconstruction Following Mastectomy (NCD 140.2), 1997. Available at: https://www.cms.gov/medicare-coverage-database/details/ncd-details.aspx? NCDId=64\&ncdver=1\&bc=AgAAQAAAAAAAAA\%3D\%3D\& Accessed November 17, 2020.

11. USA Congress. Women's Health and Cancer Rights Act. H.R. 616, 105th Cong, 1998. Available at: https://www.congress.gov/bill/105th-congress/house-bill/616 Accessed November 17, 2020.

12. Florida Senate. Senate Bill 876: Insurance Coverage for Devices Incident to Mastectomy. Statute 627.6417, 2016. Available at: https://www.flsenate.gov/Session/Bill/2016/876/BillText/Filed/HTML. Accessed November 17, 2020.

13. Xie Y, Tang Y, Wehby GL (2015). Federal Health Coverage Mandates and Health Care Utilization: The Case of the Women's Health and Cancer Rights Act and Use of Breast Reconstruction Surgery. J Womens Health (Larchmt); 24: 655-662. doi: 10.1089/jwh.2014.5057

14. Shippee TP, Kozhimannil KB, Rowan K, Virnig BA (2014). Health insurance coverage and racial disparities in breast reconstruction after mastectomy. Womens Health Issues; 24: e261-269. doi: 10.1016/j.whi.2014.03.001

15. Butler PD, Familusi O, Serletti JM, Fox JP (2018) Influence of race, insurance status, and geographic access to plastic surgeons on immediate breast reconstruction rates. Am J Surg; 215: 987-994. doi: 10.1016/j.amjsurg.2017.09.037

16. Christian CK, Niland J, Edge SB et al (2006) A multi-institutional analysis of the socioeconomic determinants of breast reconstruction: a study of the National Comprehensive Cancer Network. Ann Surg 2006; 243: 241-249. doi: 10.1097/01.sla.0000197738.63512.23

17. Coburn N, Fulton J, Pearlman DN et al (2008) Treatment variation by insurance status for breast cancer patients. Breast J; 14: 128-134. doi: 10.1111/j.1524-4741.2007.00542.x 
18. Sisco M, Du H, Warner JP et al (2012). Have we expanded the equitable delivery of postmastectomy breast reconstruction in the new millennium? Evidence from the national cancer data base. J Am Coll Surg; 215: 658-666; discussion 666. doi: 10.1016/j.jamcollsurg.2012.07.008

19. von Elm E, Altman DG, Egger M et al (2014) The Strengthening the Reporting of Observational Studies in Epidemiology (STROBE) Statement: guidelines for reporting observational studies. Int J Surg; 12: 1495-1499. doi: 10.1016/j.ijsu.2014.07.013

20. Hart A, Funderburk CD, Chu CK et al (2017) The Impact of Diabetes Mellitus on Wound Healing in Breast Reconstruction. Ann Plast Surg; 78: 260-263. doi: 10.1097/SAP.0000000000000881

21. Fischer JP, Wes AM, Kanchwala S, Kovach SJ (2014) Effect of BMI on modality-specific outcomes in immediate breast reconstruction (IBR)-a propensity-matched analysis using the 2005-2011 ACS-NSQIP datasets. J Plast Surg Hand Surg; 48: 297-304. doi: 10.3109/2000656X.2013.877915

22. In H, Jiang W, Lipsitz SR et al (2013) Variation in the utilization of reconstruction following mastectomy in elderly women. Ann Surg Oncol; 20: 1872-1879. doi: 10.1245/s10434-012-2821-5

23. McCarthy CM, Mehrara BJ, Riedel E et al (2008) Predicting complications following expander/implant breast reconstruction: an outcomes analysis based on preoperative clinical risk. Plast Reconstr Surg; 121: 1886-1892. doi: 10.1097/PRS.0b013e31817151c4

24. US Census Bureau. Income Statistics for Florida Zip Codes. Florida, USA. Available at: https://www.incomebyzipcode.com/florida. Accessed November 17, 2020.

25. Mayhew D, Mendonca V, Murthy BVS (2019) A review of ASA physical status - historical perspectives and modern developments. Anaesthesia; 74: 373-379. doi: 10.1111/anae.14569

26. Giuliano AE, Edge SB, Hortobagyi GN (2018) Eighth Edition of the AJCC Cancer Staging Manual: Breast Cancer. Ann Surg Oncol. Jul;25(7):1783-1785. doi: 10.1245/s10434-018-6486-6

27. Rusthoven CG, Rabinovitch RA, Jones BL et al. The impact of postmastectomy and regional nodal radiation after neoadjuvant chemotherapy for clinically lymph node-positive breast cancer: a National Cancer Database (NCDB) analysis. Ann Oncol. 2016 May;27(5):818-27. doi: 10.1093/annonc/mdw046.

28. Yun JH, Diaz R, Orman AG. Breast Reconstruction and Radiation Therapy. Cancer Control. 2018;25(1):1073274818795489. doi:10.1177/1073274818795489

29. Flegal KM, Kit BK, Orpana H, Graubard BI (2013) Association of all-cause mortality with overweight and obesity using standard body mass index categories: a systematic review and meta-analysis. JAMA; 309: 71-82. doi: 10.1001/jama.2012.113905

30. Kruper L, Holt A, Xu XX et al (2011) Disparities in reconstruction rates after mastectomy: patterns of care and factors associated with the use of breast reconstruction in Southern California. Ann Surg Oncol; 
31. Niu X, Roche LM, Pawlish KS, Henry KA (2013). Cancer survival disparities by health insurance status. Cancer Med; 2: 403-411. doi: 10.1002/cam4.84

32. Schwartz DA, Hui X, Schneider EB et al (2014) Worse outcomes among uninsured general surgery patients: does the need for an emergency operation explain these disparities? Surgery; 156: 345-351. doi: 10.1016/j.surg.2014.04.039

33. McMorrow S, Long SK, Kenney GM, Anderson N. Uninsurance Disparities Have Narrowed For Black And Hispanic Adults Under The Affordable Care Act. Health Aff (Millwood). 2015;34(10):1774-1778.

34. Neuhausen K, Davis AC, Needleman J et al (2014) Disproportionate-share hospital payment reductions may threaten the financial stability of safety-net hospitals. Health Aff (Millwood); 33: 988-996. doi: $10.1377 /$ hlthaff.2013.1222

35. Hoehn RS, Wima K, Vestal MA et al (2016) Effect of Hospital Safety-Net Burden on Cost and Outcomes After Surgery. JAMA Surg; 151: 120-128. doi: 10.1001/jamasurg.2015.3209

36. Hershman DL, Richards CA, Kalinsky K et al (2012) Influence of health insurance, hospital factors and physician volume on receipt of immediate post-mastectomy reconstruction in women with invasive and non-invasive breast cancer. Breast Cancer Res Treat; 136: 535-545. doi: 10.1007/s10549-012-2273-4

37. Alderman AK, Hawley ST, Janz NK et al (2009) Racial and ethnic disparities in the use of postmastectomy breast reconstruction: results from a population- based study. J Clin Oncol; 27: 53255330. doi: $10.1200 / J C 0.2009 .22 .2455$

38. Hong KY, Son Y, Chang H, Jin US (2018) Trends in breast reconstruction: Implications for the National Health Insurance Service. Arch Plast Surg; 45: 239-245. doi: 10.5999/aps.2017.01417

39. Freeman JD, Kadiyala S, Bell JF, Martin DP (2008). The causal effect of health insurance on utilization and outcomes in adults: a systematic review of US studies. Med Care; 46: 1023-1032. doi: 10.1097/MLR.0b013e318185c913

40. Hadley J. (2003) Sicker and poorer-the consequences of being uninsured: a review of the research on the relationship between health insurance, medical care use, health, work, and income. Med Care Res Rev; 60: 3S-75S; discussion 76S-112S. doi: 10.1177/1077558703254101

41. Sommers BD, Blendon RJ, Orav EJ, Epstein AM (2016) Changes in Utilization and Health Among Low-Income Adults After Medicaid Expansion or Expanded Private Insurance. JAMA Intern Med; 176: 1501-1509. doi: 10.1001/jamainternmed.2016.4419.

42. Ayanian JZ, Weissman JS, Schneider EC et al (2000). Unmet health needs of uninsured adults in the United States. JAMA; 284: 2061-2069. doi: 10.1001/jama.284.16.2061 
43. Baker DW, Shapiro MF, Schur CL (2000) Health insurance and access to care for symptomatic conditions. Arch Intern Med; 160: 1269-1274. doi: 10.1001/archinte.160.9.1269

44. Lillie-Blanton M, Hoffman C (2005). The role of health insurance coverage in reducing racial/ethnic disparities in health care. Health Aff (Millwood); 24: 398-408. doi: 10.1377/hlthaff.24.2.398

45. Shah NS, Carrasquillo $O$ (2006). Twelve-year trends in health insurance coverage among Latinos, by subgroup and immigration status. Health Aff (Millwood); 25: 1612-1619. doi: 10.1377/hlthaff.25.6.1612

46. Prentice JC, Pebley AR, Sastry N (2005) Immigration status and health insurance coverage: who gains? Who loses? Am J Public Health; 95: 109-116. doi: 10.2105/AJPH.2003.028514

47. Bradford J, Reisner SL, Honnold JA, Xavier J (2013). Experiences of transgender-related discrimination and implications for health: results from the Virginia Transgender Health Initiative Study. Am J Public Health; 103: 1820-1829. doi: 10.2105/AJPH.2012.300796

48. United States Census Bureau, Department of Commerce. Health Insurance Coverage in the United States: 2018. In Current Population Reports. Washington, DC, United States. Available at: Health Insurance Coverage in the United States: 2018 (census.gov), Accessed December 16, 2020.

\section{Figures}




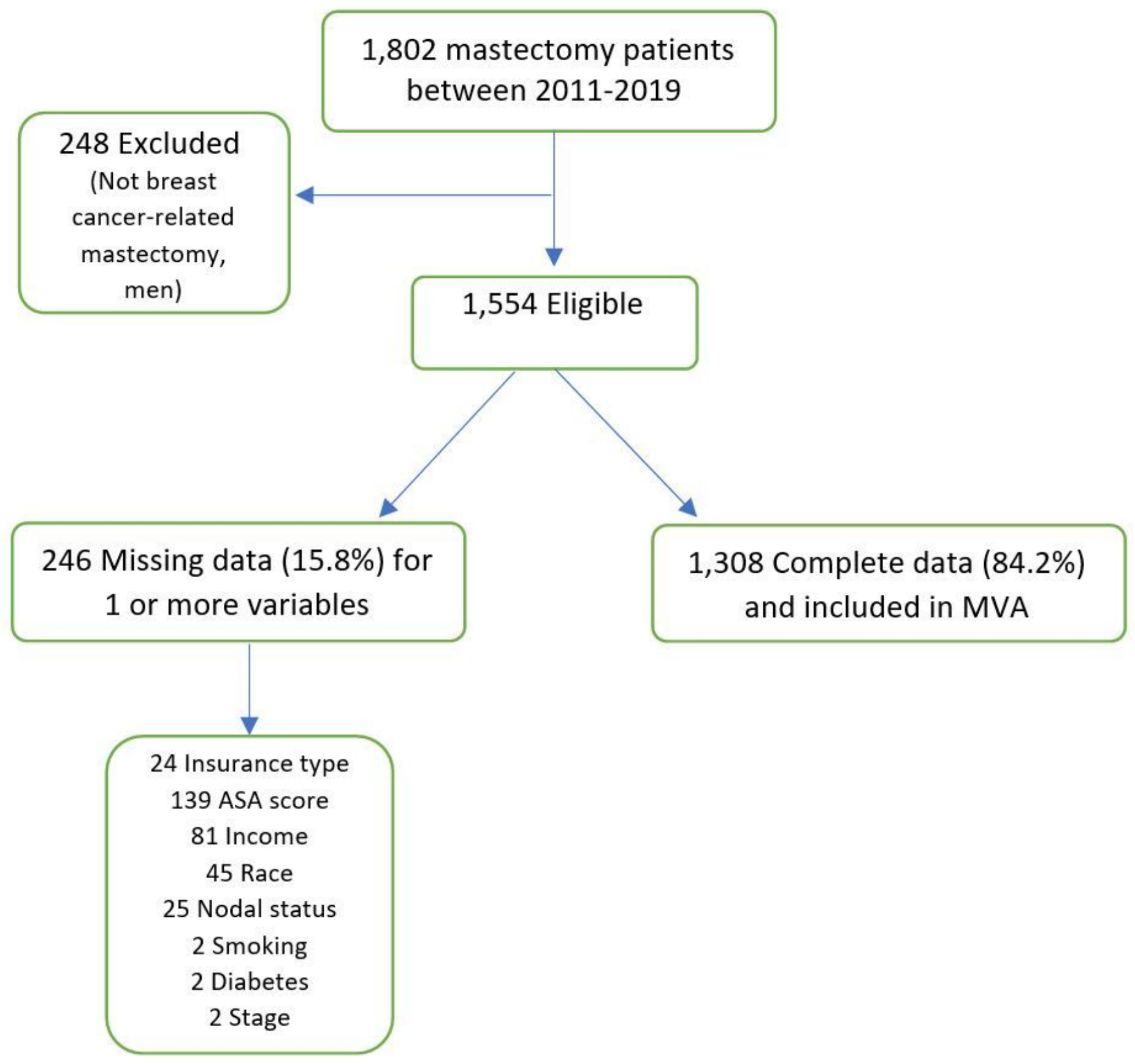

Figure 1

Flowchart of patients' eligibility and completeness of data. ASA American Society of Anesthesiologists, MVA, multivariable analysis. 